\title{
One-Pot Synthesis of Dendritic Polyamide III. Dendritic Polyamide from 5-[3-(4-Aminophenyl)propionylamino]isophthalic Acid Hydrochloride and 1,1,1-Tris(4-carboxymethyloxyphenyl)ethane as a Core Molecule
}

\author{
Teruaki Hayakawa, ${ }^{*}, * * * *$ Yoshitaka Yamakawa, ${ }^{* *}$ Masayoshi NomURA, ${ }^{*}$ \\ Masaki OKAZAKI, ${ }^{* * *}$ Kazuhiko TAKeUCHI, ${ }^{* * *}$ Michihiko ASAI, ${ }^{* * * *}$ and Mitsuru UEDA ${ }^{*}, * *, * * *$ \\ ${ }^{*}$ Human Sensing and Functional Sensor Engineering, Graduate School of Engineering, \\ Yamagata University, Yonezawa, Yamagata 992-8510, Japan \\ ** Joint Research Center for Precision Polymerization, Japan Chemical Innovation Institute, \\ 1-1 Higashi, Tsukuba, Ibaraki 305-8565 Japan \\ *** Department of Organic and Polymeric Materials, Tokyo Institute of Technology, \\ Ohokayama, Meguro-ku, Tokyo 152-8552, Japan \\ **** National Institute of Materials and Chemical Research, \\ 1-1 Higashi, Tsukuba, Ibaraki 305-8565 Japan
}

(Received March 28, 2000; Accepted May 10, 2000)

\begin{abstract}
One-pot synthesis of the dendritic polyamides from the 1st to the 4th generations with a very narrow molecular weight distribution was performed by condensation of 1,1,1-tris(4-carboxymethyloxyphenyl)ethane as a core molecule with aminodicarboxylic acid using the condensing agent, diphenyl(2,3-dihydro-2-thioxo-3-benzoxazolyl)phosphonate (DBOP) in $N$-methyl-2-pyrrolidinone (NMP). Activation and condensation reactions were each completed in 30 min. All dendritic polyamides were obtained quantitatively and fully characterized by IR and NMR spectroscopy. Number average molecular weights $\left(M_{n}\right)$ of dendritic polyamides were estimated by end group analysis and each dendritic polyamide had $M_{n}$ close to the calculated value. Molecular weight distribution was $1.07-1.09$ as measured by GPC using THF as eluent. The degree of branching for the third generation dendritic polyamide was 0.91 .

KEY WORDS Dendritic Polyamide / Dendrimer / One-Pot Synthesis / Diphenyl(2,3-dihydro-2-thioxo3-benzoxazolyl)phosphonate / Degree of Branching / Large Scale Synthesis / Molecular Weight Distribution /
\end{abstract}

Dendrimers are well defined, highly branched, threedimensional compounds with a large number of reactive end groups. Therefore, they are of great interest as new polymeric materials whose properties should differ significantly from those of linear polymers. ${ }^{1}$ Divergent and convergent methods are synthetic routes for dendrimers. $^{2,3}$ They require tedious multi-step procedures involving repetitive protection-deprotection reactions. A new synthetic approach with no protection/deprotection and extended purification steps should be developed for large-scale synthesis of dendrimers. ${ }^{4-7}$ We have been studying rapid synthetic processes of dendrimers. ${ }^{8,9} \mathrm{~A}$ previous paper $^{10}$ reported that dendritic polyamides having a high degree of branching and low dispersity were prepared by a "one-pot" procedure which consists of successive activation of carboxyl groups, followed by condensation with aminodicarboxylic acid. Molecular weight distribution broadened with generation because of the formation of side products. Trimesic acid as a core molecule is so small that steric hindrance would interfere with coupling reactions of dendron and end groups of dendrimer.

We investigated in more detail reaction of $p$-toluic acid and aminodicarboxylic acid in the presence of the condensing agent, diphenyl(2,3-dihydro-2-thioxo-3-benzoxazolyl)phosphonate (DBOP), and found that the desired product without the side product was obtained quantitatively.

This paper describes a one-pot synthesis of dendritic polyamides with a very narrow molecular weight distribution from 1,1,1-tris(4-carboxymethyloxyphenyl)ethane (1) as a large core and a dendron, aminodicarboxylic acid
(2) (Scheme 1).

\section{EXPERIMENTAL}

\section{Materials}

$N$-Methyl-2-pyrrolidinone (NMP) was distilled under reduced pressure and stored over 4-A molecular sieves. Triethylamine (TEA) was purified by the usual method. DBOP as condensing agent was prepared as reported. ${ }^{11}$ The other reagents were obtained commercially and used as received.

Synthesis of Core: 1,1,1-Tris(4-carboxymethyloxyphenyl)ethane (1)

A solution of methyl bromoacetate $(14.2 \mathrm{~g}, 93.0 \mathrm{mmol})$

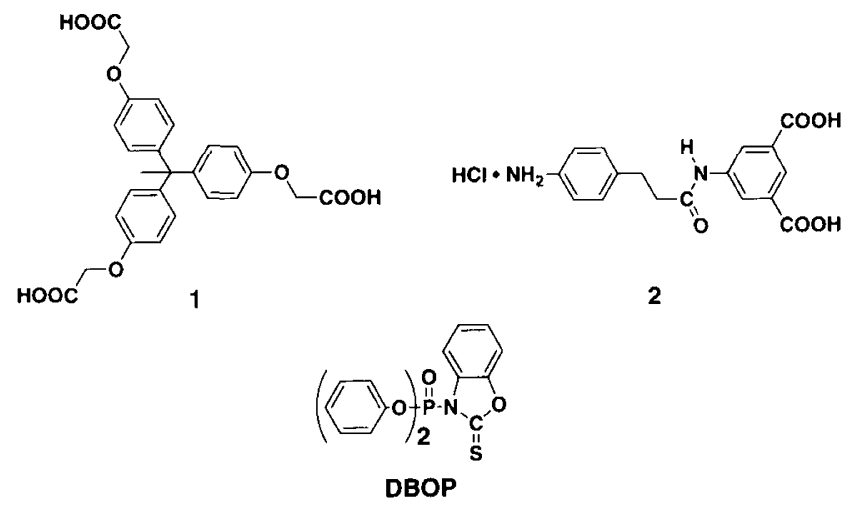

Scheme 1. 
in acetone $(30 \mathrm{~mL})$ was added dropwise to a solution of 1,1,1-tris(4-hydroxyphenyl)ethane ( $7.3 \mathrm{~g}, 23.8 \mathrm{mmol}$ ), potassium carbonate $(12.8 \mathrm{~g}, 93.0 \mathrm{mmol})$, and potassium iodide $(0.15 \mathrm{~g}, 0.92 \mathrm{mmol})$ in acetone $(90 \mathrm{~mL})$ at room temperature under nitrogen atomosphere. The mixture was refluxed for $24 \mathrm{~h}$, cooled to room temperature and extracted with ethyl acetate. The combined organic layer was washed with aqueous $10 \mathrm{wt} \%$ sodium hydrogencarbonate and saturated sodium chloride solution, dried over anhydrous magnesium sulfate, and filtered. After evaporation of the solvent, the white residue was stirred with aqueous $1 \mathrm{M}$ sodium hydroxide solution $(90 \mathrm{~mL})$ at $70^{\circ} \mathrm{C}$ for $24 \mathrm{~h}$, and cooled to room temperature. Target core 1 was obtained by addition of $36 \%$ hydrochloric acid to the solution. Yield: $90 \% . \mathrm{mp} 171-172^{\circ} \mathrm{C}$. IR $(\mathrm{KBr}): v$ $\left(\mathrm{cm}^{-1}\right)=3200-2400,(\mathrm{OH}, \mathrm{st}), 1700(\mathrm{C}=\mathrm{O}, \mathrm{st}), 1600$, 1515 (benzene ring, st), $1240\left(\mathrm{C}-\mathrm{O}-\mathrm{C}\right.$, st). ${ }^{1} \mathrm{H}$ NMR $\left(300 \mathrm{MHz},\left(\mathrm{CD}_{3}\right)_{2} \mathrm{SO}\right) \delta(\mathrm{ppm})=2.01\left(\mathrm{~s}, \mathrm{CH}_{3}, 3 \mathrm{H}\right), 4.61(\mathrm{~s}$, $\left.\mathrm{CH}_{2}, 6 \mathrm{H}\right), 6.79$ (d, Ar, $\left.J=9.0 \mathrm{~Hz}, 6 \mathrm{H}\right), 6.91$ (d, Ar, $J=$ $9.0 \mathrm{~Hz}, 6 \mathrm{H})$. Anal. Calcd. for $\mathrm{C}_{26} \mathrm{H}_{24} \mathrm{O}_{9}: \mathrm{C}, 65.00 ; \mathrm{H}, 5.03$. Found: C, 64.90; H, 5.07.

Synthesis of Dendron: 5-[3-(4-Aminophenyl) propionylamino 7 isophthalic Acid hydrochloride (2)

Compound 2 was prepared by a reported procedure. ${ }^{10}$

\section{Model Reaction}

DBOP $(0.1983 \mathrm{~g}, 0.517 \mathrm{mmol})$ was added to a solution of $p$-toluic acid (3) $(0.0680 \mathrm{~g}, 0.50 \mathrm{mmol})$ and TEA $(0.143 \mathrm{~mL}, 1.035 \mathrm{mmol})$ in NMP $(1.0 \mathrm{~mL})$ at room temperature. After the solution was stirred for $30 \mathrm{~min}$, dendron $2(0.1823 \mathrm{~g}, 0.50 \mathrm{mmol})$ was added and the solution was stirred at this temperature for $30 \mathrm{~min}$. TEA (0.143 mL, $1.035 \mathrm{mmol})$, NMP (1.0 mL), DBOP (0.3967 g, $1.035 \mathrm{mmol})$, and 4-t-butylaniline (4) $(0.162 \mathrm{~mL}$, $1.035 \mathrm{mmol}$ ) were added and the mixture was stirred, poured into aqueous $1 \mathrm{wt} \%$ sodium hydrogencarbonate solution and the precipitate was collected by filtration. The product (5) was washed with water and dried in vacuo at $50^{\circ} \mathrm{C}$. Recrystallization from ethyl acetate afforded white crystals. Yield: $95 \%$. mp 203-204 ${ }^{\circ} \mathrm{C}$. IR $(\mathrm{KBr}): v\left(\mathrm{~cm}^{-1}\right)=1655(\mathrm{C}=\mathrm{O}$, st), 1600, 1515 (benzene ring, st). ${ }^{1} \mathrm{H} \mathrm{NMR}\left(300 \mathrm{MHz},\left(\mathrm{CD}_{3}\right)_{2} \mathrm{SO}\right) \delta(\mathrm{ppm})=1.27$ $\left(\mathrm{s}, \mathrm{CH}_{3}, 18 \mathrm{H}\right), 2.36\left(\mathrm{~s}, \mathrm{CH}_{3}, 3 \mathrm{H}\right), 2.69\left(\mathrm{t}, J=6.9 \mathrm{~Hz}, \mathrm{CH}_{2}\right.$, $2 \mathrm{H}), 2.89\left(\mathrm{t}, J=6.9 \mathrm{~Hz}, \mathrm{CH}_{2}, 2 \mathrm{H}\right), 7.23(\mathrm{~d}, \mathrm{Ar}, J=8.7 \mathrm{~Hz}$, $2 \mathrm{H}), 7.31(\mathrm{~d}, \mathrm{Ar}, J=7.8 \mathrm{~Hz}, 2 \mathrm{H}), 7.37(\mathrm{~d}, \mathrm{Ar}, J=8.7 \mathrm{~Hz}$, $4 \mathrm{H}), 7.68$ (Ar, $6 \mathrm{H}), 7.84(\mathrm{~d}, \mathrm{Ar}, J=7.8 \mathrm{~Hz}, 2 \mathrm{H}), 8.14$ (s, $\mathrm{Ar}, 1 \mathrm{H}), 8.28$ (s, Ar, 2H), 10.08 (s, N-H, 1H), 10.31 (s, N$\mathrm{H}, 1 \mathrm{H}), 10.34(\mathrm{~s}, \mathrm{~N}-\mathrm{H}, 2 \mathrm{H})$. Anal. Calcd. for $\mathrm{C}_{45} \mathrm{H}_{48} \mathrm{~N}_{4} \mathrm{O}_{4}$ : C, 76.24; H, 6.82; N, 7.90. Found: C, 76.10; H, 6.60; N, 7.81 .

\section{Synthesis of Dendrimers ( $7 \boldsymbol{a}-7 \boldsymbol{e})$ : General Procedure}

To a solution of 1 in NMP, 3.105 equivalents of DBOP and TEA toward 1 were added. The solution was stirred at room temperature for $30 \mathrm{~min}$. 3.0 equivalents of 2 to 1 were added to the solution and condensation was performed at room temperature for $30 \mathrm{~min}$. This procedure was repeated several times. Finally, the terminal carboxyl groups were end-capped with 1.035 equivalents of 4 or diethylamine (6) and DBOP to the carboxyl group. The reaction mixture was poured into aqueous $1 \mathrm{wt} \%$ sodium hydrogencarbonate solution and the precipitate was collected by filtration. The product was washed with methanol and dried in vacuo at $50^{\circ} \mathrm{C}$.

\section{1st Generation Dendritic Polyamide (7a)}

Yield : 91\%. IR (KBr): $v\left(\mathrm{~cm}^{-1}\right)=3290(\mathrm{~N}-\mathrm{H}, \mathrm{st}), 1655$ $\left(\mathrm{C}=\mathrm{O}\right.$, st), 1600,1515 (benzene ring, st). ${ }^{1} \mathrm{H}$ NMR $\left(300 \mathrm{MHz},\left(\mathrm{CD}_{3}\right)_{2} \mathrm{SO}\right) \delta(\mathrm{ppm})=1.27\left(\mathrm{CH}_{3}, 54 \mathrm{H}\right), 2.01$ $\left(\mathrm{CH}_{3}, 3 \mathrm{H}\right), 2.71\left(\mathrm{CH}_{2}, 6 \mathrm{H}\right), 2.89\left(\mathrm{CH}_{2}, 6 \mathrm{H}\right), 4.60\left(\mathrm{CH}_{2}\right.$, $6 \mathrm{H}), 6.85,6.89,7.20,7.28,7.36,7.52,7.67,8.14,8.26$, $8.28(\mathrm{Ar}-\mathrm{H}, 57 \mathrm{H}), 9.96,10.29,10.34,10.39(\mathrm{~N}-\mathrm{H}, 12 \mathrm{H})$. Anal. Calcd. for $\mathrm{C}_{137} \mathrm{H}_{144} \mathrm{~N}_{12} \mathrm{O}_{15} 8.6 \mathrm{H}_{2} \mathrm{O}: \mathrm{C}, 69.88 ; \mathrm{H}$, 6.16 ; N, 7.13. Found: C, 69.88; H, 6.62; N, 7.64.

\section{2nd Generation Dendritic Polyamide ( $7 \boldsymbol{b})$}

Yield : 94\%. IR (KBr): $v\left(\mathrm{~cm}^{-1}\right)=3290(\mathrm{~N}-\mathrm{H}, \mathrm{st}), 1655$ (C=O, st), 1600, 1515 (benzene ring, st). ${ }^{1} \mathrm{H}$ NMR $\left(300 \mathrm{MHz},\left(\mathrm{CD}_{3}\right)_{2} \mathrm{SO}\right) \delta(\mathrm{ppm})=1.26\left(\mathrm{CH}_{3}, 108 \mathrm{H}\right), 2.01$ $\left(\mathrm{CH}_{3}, 3 \mathrm{H}\right), 2.68\left(\mathrm{CH}_{2}, 18 \mathrm{H}\right), 2.90\left(\mathrm{CH}_{2}, 18 \mathrm{H}\right), 4.61\left(\mathrm{CH}_{2}\right.$, $6 \mathrm{H}), 6.86,6.92,7.20,7.22,7.27,7.36,7.53,7.68,8.14$, 8.25, 8.28 (Ar-H, 123H), 9.97, 10.28, 10.32, $10.34(\mathrm{~N}-\mathrm{H}$, $30 \mathrm{H}$ ). Anal. Calcd. for $\mathrm{C}_{299} \mathrm{H}_{306} \mathrm{~N}_{30} \mathrm{O}_{33} 11.9 \mathrm{H}_{2} \mathrm{O}: \mathrm{C}, 70.93$; $\mathrm{H}, 6.09$; N, 8.30. Found: C, 70.95; H, 6.51; N, 8.11.

\section{3rd Generation Dendritic Polyamide ( $7 \boldsymbol{c}$ )}

Yield : 98\%. IR (KBr): $v\left(\mathrm{~cm}^{-1}\right)=3290(\mathrm{~N}-\mathrm{H}, \mathrm{st}), 1655$ $\left(\mathrm{C}=\mathrm{O}\right.$, st), 1600,1515 (benzene ring, st). ${ }^{1} \mathrm{H} \mathrm{NMR}$ $\left(300 \mathrm{MHz},\left(\mathrm{CD}_{3}\right)_{2} \mathrm{SO}\right) \delta(\mathrm{ppm})=1.27\left(\mathrm{CH}_{3}, 216 \mathrm{H}\right), 2.01$ $\left(\mathrm{CH}_{3}, 3 \mathrm{H}\right), 2.69\left(\mathrm{CH}_{2}, 42 \mathrm{H}\right), 2.91\left(\mathrm{CH}_{2}, 42 \mathrm{H}\right), 4.61\left(\mathrm{CH}_{2}\right.$, $6 \mathrm{H}), 6.87,6.91,7.21,7.23,7.28,7.36,7.54,7.70,8.15$, 8.24, 8.28 (Ar-H, 255H), 9.98, 10.29, 10.35, $10.39(\mathrm{~N}-\mathrm{H}$, $66 \mathrm{H})$. Anal. Calcd. for $\mathrm{C}_{623} \mathrm{H}_{630} \mathrm{~N}_{66} \mathrm{O}_{69} 19.1 \mathrm{H}_{2} \mathrm{O}: \mathrm{C}, 71.32$; $\mathrm{H}, 6.05 ; \mathrm{N}, 8.81$. Found: C, 71.33; H, 6.47; N, 8.56.

\section{4th Generation Dendritic Polyamide (7d)}

Yield : 95\%. IR (KBr): $v\left(\mathrm{~cm}^{-1}\right)=3290(\mathrm{~N}-\mathrm{H}$, st $), 1655$ (C=O, st), 1600, 1515 (benzene ring, st). ${ }^{1} \mathrm{H}$ NMR (300 $\left.\mathrm{MHz}, \quad\left(\mathrm{CD}_{3}\right)_{2} \mathrm{SO}\right) \quad \delta(\mathrm{ppm})=1.27 \quad\left(\mathrm{CH}_{3}, 432 \mathrm{H}\right), 2.02$ $\left(\mathrm{CH}_{3}, 3 \mathrm{H}\right), 2.70\left(\mathrm{CH}_{2}, 90 \mathrm{H}\right), 2.93\left(\mathrm{CH}_{2}, 90 \mathrm{H}\right), 3.25\left(\mathrm{CH}_{2}\right.$, $32 \mathrm{H}), 4.73\left(\mathrm{CH}_{2}, 6 \mathrm{H}\right), 6.84,6.95,7.17,7.21,7.27,7.29$, 7.36, 7.39, 7.54, 7.67, 7.69, 7.70, 7.88, 8.12, 8.17, 8.30, $8.57(\mathrm{Ar}-\mathrm{H}, 519 \mathrm{H}), 9.63,10.02,10.39(\mathrm{~N}-\mathrm{H}, 138 \mathrm{H})$. Anal. Calcd. for $\mathrm{C}_{1271} \mathrm{H}_{1278} \mathrm{~N}_{138} \mathrm{O}_{141} 35.1 \mathrm{H}_{2} \mathrm{O}$ : C, 71.42; H, 6.03; $\mathrm{N}, 9.04$. Found: C, 71.43; H, 6.31; N, 9.05.

\section{3rd Generation Dendritic Polyamide (7e)}

Diethylamine (6) was used as the end-capped reagent for terminal carboxyl groups of 7e. Yield : 98\%. IR $(\mathrm{KBr}): v\left(\mathrm{~cm}^{-1}\right)=3290(\mathrm{~N}-\mathrm{H}, \mathrm{st}), 1655(\mathrm{C}=\mathrm{O}, \mathrm{st}), 1600$, 1515 (benzene ring, st). ${ }^{1} \mathrm{H}$ NMR $\left(300 \mathrm{MHz},\left(\mathrm{CD}_{3}\right)_{2} \mathrm{SO}\right) \delta$ $(\mathrm{ppm})=1.11 \quad\left(\mathrm{CH}_{3}, \quad 48 \mathrm{H}\right), \quad 2.05 \quad\left(\mathrm{CH}_{3}, \quad 3 \mathrm{H}\right), \quad 2.66$ $\left(\mathrm{CH}_{2}, 42 \mathrm{H}\right), 2.93\left(\mathrm{CH}_{2}, 42 \mathrm{H}\right), 3.25\left(\mathrm{CH}_{2}, 32 \mathrm{H}\right), 4.73\left(\mathrm{CH}_{2}\right.$, $6 \mathrm{H}), 6.97,7.00,7.26,7.54,7.62,7.66,7.88,8.09,8.17$, $8.30(\mathrm{Ar}-\mathrm{H}, 159 \mathrm{H}), 9.85,10.05,10.15,10.16,10.23(\mathrm{~N}-\mathrm{H}$, $42 \mathrm{H}$ ). Anal. Calcd. for $\mathrm{C}_{479} \mathrm{H}_{534} \mathrm{~N}_{66} \mathrm{O}_{69} 11.9 \mathrm{H}_{2} \mathrm{O}: \mathrm{C}, 67.40$; H, 6.31; N, 10.82. Found: C, 67.41; H, 6.65; N, 10.82.

\section{Measurement}

Infrared spectra were recorded on a Horiba FT-720 spectrophotometer. ${ }^{1} \mathrm{H}$ and ${ }^{13} \mathrm{C}$ NMR spectra were obtained on a BRUKER DPX-300 spectrometer at ${ }^{1} \mathrm{H}$, $300 \mathrm{MHz}$ and ${ }^{13} \mathrm{C}, 67.5 \mathrm{MHz}$, respectively. Deuterated dimethylsulfoxide was used as solvent with tetramethylsilane as internal standard. Gel permeation chromatog- 


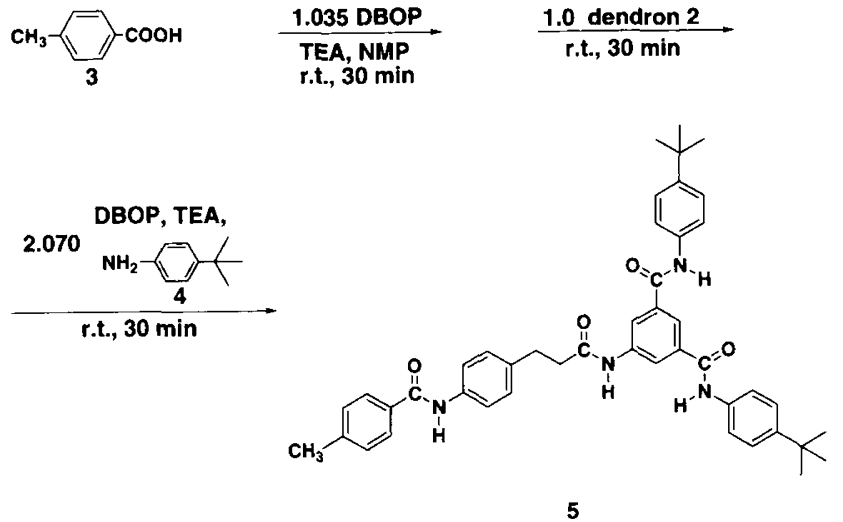

Scheme 2.
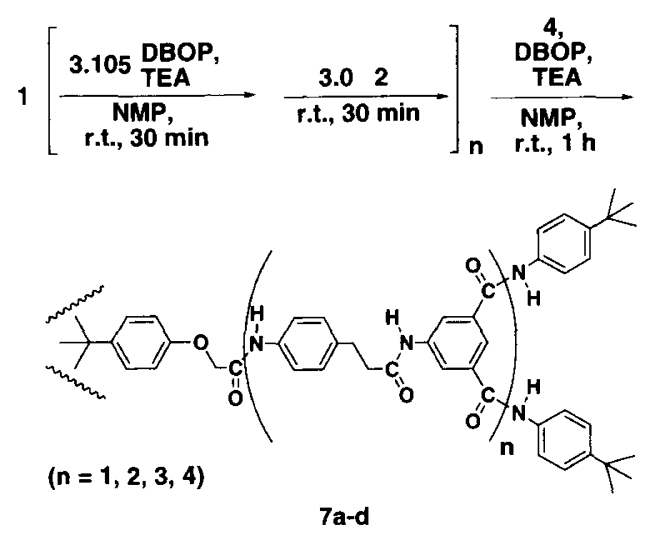

Scheme 3. raphy (GPC) was performed with a HITACHI L-7100 pump, HITACHI L-7300 column oven, and HITACHI L7400 UV detector fixed at $254 \mathrm{~nm}$ (column, GL-A150-S; standard, polystyrene; solvent, THF; Temp, $40^{\circ} \mathrm{C}$; flow rate, $1.0 \mathrm{~mL} \mathrm{~min}^{-1}$ ).

\section{RESULTS AND DISCUSSION}

We initially studied the reaction of $p$-toluic acid 3 with dendron 2 to determine whether model compound (5) was formed in quantitative yield without a side product (Scheme 2). The model reaction was carried out in the presence of the condensing reagent DBOP and TEA in NMP at room temperature. The amounts of DBOP and TEA were very important to eliminate the side reaction, and the optimum molar ratio of DBOP and TEA to the carboxyl group was found to be 1.035 .

3 was activated with 1.035 equivalents of the condensing agent DBOP in the presence of 1.035 equivalents of TEA to the carboxyl group at room temperature for $30 \mathrm{~min}$, followed by condensation with 1.0 equivalent of 2 to 3 . Condensation was carried out for $30 \mathrm{~min}$, and two carboxyl groups of the resulting amide were capped with $t$-butylaniline 4 in the presence of DBOP. The reaction mixture was poured into aqueous $1 \mathrm{wt} \%$ sodium hydrogencarbonate solution and the precipitate was filtered. Yield of product $\mathbf{5}$ was $95 \%$. The side product in the previous paper was not detected by thin layer chromatography (TLC). The structure of product $\mathbf{5}$ was characterized IR and NMR spectroscopy.

Synthesis of Dendritic Polyamides: From 1st to 4th Generations

Based on the model reaction, dendritic polyamides from $\mathbf{7 a}$ to $\mathbf{7 d}$ were synthesized divergently by reaction of 1,1,1-tris(4-carboxymethyloxyphenyl)ethane $\mathbf{1}$ with 2 using DBOP (Scheme 3). Compound 1 was used as the large core molecule. The carboxyl groups of 1 were activated with 3.105 equivalents of DBOP and TEA in NMP at room temperature for $30 \mathrm{~min}$. 3.0 equivalents of 2 to 1 were added to the solution, and the mixture was stirred at this temperature for $30 \mathrm{~min}$. 1.035 equivalents of DBOP to the carboxyl group were added to solution for the activation of the amide. This procedure was repeated several times for preparation of target dendritic poly- mers. Carboxyl group concentration in the reaction was kept at $0.10 \mathrm{~mol} \mathrm{~L}^{-1}$. 1.035 equivalents of 4 to the carboxyl group as capping agent were added to the solution. After $30 \mathrm{~min}$, the solution was poured into aqueous $1 \mathrm{wt} \%$ sodium hydrogencarbonate solution and the white precipitate was filtered, washed with methanol, and dried in vacuo. The yields of dendritic polyamides $\mathbf{7 a}-$ 7d were $91-98 \%$.

\section{Characterization of Dendritic Polyamides}

IR, NMR, and GPC measurements were carried out for characterization of $\mathbf{7 a - 7 d}$. The IR spectra of all dendritic polyamides showed strong carbonyl peaks at $1655 \mathrm{~cm}^{-1}$ due to amide linkages and no carbonyl signals due to carboxyl groups at $1700 \mathrm{~cm}^{-1}$ or the active amides at $1720 \mathrm{~cm}^{-1}$ were detected, thereby confirming all terminal carboxyl groups to be end-capped with 4 . In the ${ }^{1} \mathrm{H}$ NMR spectra, integrated intensity of proton peaks of $\mathbf{7 a - 7 d}$ was in very good agreement with theoretical values for the core, building, and terminal units. These findings clearly indicate the formation of the desired dendritic polyamides. ${ }^{1} \mathrm{H}$ NMR spectrum of the third generation dendritic polyamide $\mathbf{7 c}$ is shown in Figure 1 .

An important characteristic of dendritic polymer is the degree of branching (DB), because dendritic polymers contain the dendritic, terminal, and linear units as shown in Figure 2.

DBs of $\mathbf{7 a}-\mathbf{7 d}$ were difficult to estimate by ${ }^{1} \mathrm{H}$ NMR signals of these units because they overlapped each other. Therefore, using a secondary aliphatic amine, diethylamine 6 as the end-capping agent, 3rd generation dendritic polyamide $7 \mathbf{e}$ was synthesized by the same procedure. DB of 7e was determined by model compound studies and ${ }^{1} \mathrm{H}$ NMR integration of each unit as described previously. ${ }^{2} \mathrm{H}$ NMR spectrum of $7 \mathbf{e}$ is shown in Figure 3 with those of dendritic and terminal model compounds of $\mathbf{8 a}$ and $\mathbf{8 b}$.

Dendritic model compound 8a shows two peaks at 8.29 and $8.15 \mathrm{ppm}$ due to protons $d_{2}$ and $d_{1}$ of aromatic ring 9. ${ }^{10}$ Terminal model compound $\mathbf{8 b}$ shows the corresponding protons $t_{2}$ and $t_{1}$ at 7.66 and $6.94 \mathrm{ppm}$. The signals corresponding to the dendritic and terminal units in $7 \mathbf{e}$ were observed at 8.30 and $8.17,7.62$, and 6.92 . Thus, peaks at 7.88 and $8.09 \mathrm{ppm}$ are attributed to the corre- 


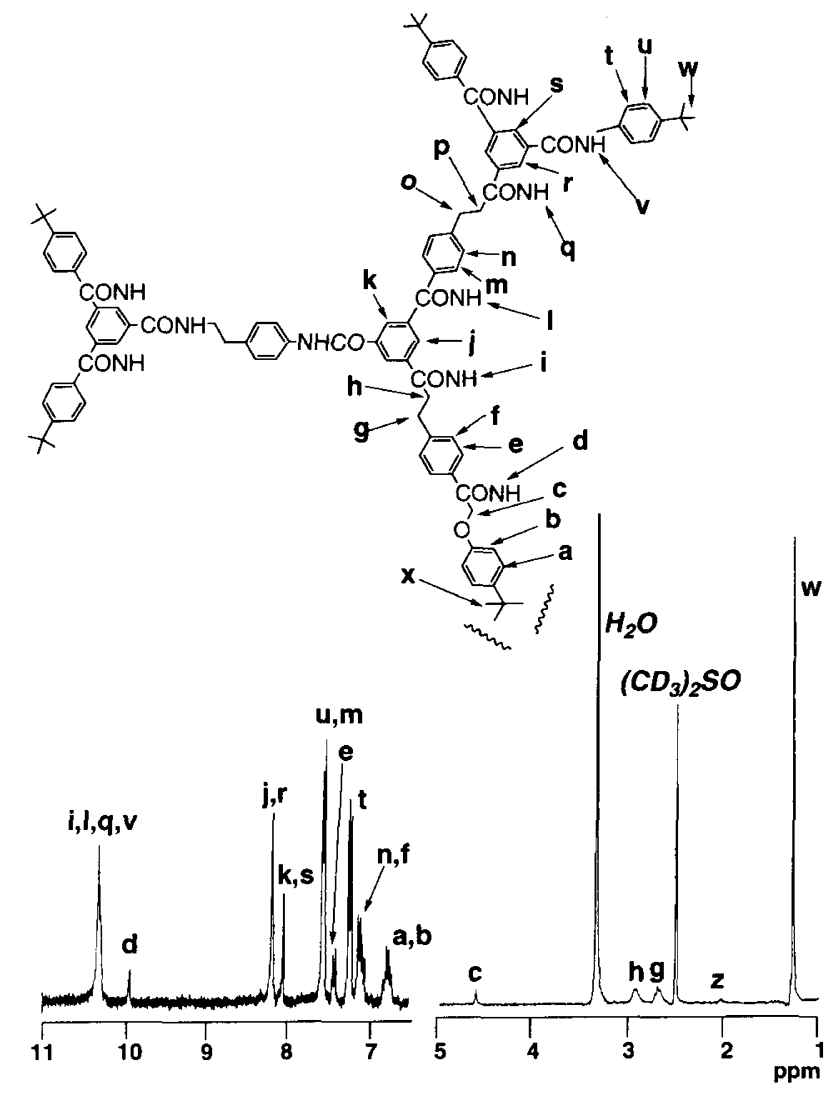

Figure 1. ${ }^{1} \mathrm{H}$ NMR spectrum of second generation dendritic polyamide $\mathbf{7 b}$ in $\left(\mathrm{CD}_{3}\right)_{2} \mathrm{SO}-d_{6}$.

sponding protons $l_{1}$ and $l_{2}$ of the linear unit of $7 \mathbf{e}$, respectively. In the ${ }^{1} \mathrm{H}^{-1} \mathrm{H}$ COSY NMR spectrum of $7 \mathbf{e}$, the signal at $7.61 \mathrm{ppm}$ due to $l_{3}$ of the linear unit overlapped with the signal of $t_{2}$. By integrated intensity of the peaks, DB was calculated the following Freys definition, ${ }^{12}$ $\mathrm{DB}=(2 \times$ number of dendritic units $) /(2 \times$ number of dendritic units + number of linear units)

Estimated DB of the 3rd generation dendritic polyamide 7e was 0.91 .

Molecular weight distribution is important to evaluate the regularity of dendritic polymers. $M_{w} / M_{n}$ was measured by GPC in THF. All chromatograms showed symmetrical unimodal peaks as shown in Figure 4.

Distributions was 1.07-1.09. The correct molecular weight of dendritic polymers cannot be obtained by GPC using polystyrene as standard. Therefore, the number average molecular weight $\left(M_{n}\right)$ of dendritic polyamides was estimated by end group analysis. Number average molecular weights were obtained by the ratio of integrated intensity for the methylene protons of the core to the terminal $t$-butyl protons of dendritic polyamides. Dendritic polyamide $M_{n}$ was close to the calculated value (Table I).

\section{CONCLUSIONS}

One-pot synthesis of dendritic polyamides $\mathbf{7 a}-\mathbf{7 d}$ was performed by condensation of the large core 1 with dendron 2 using the condensing agent DBOP in NMP. Activation and condensation reactions were completed in
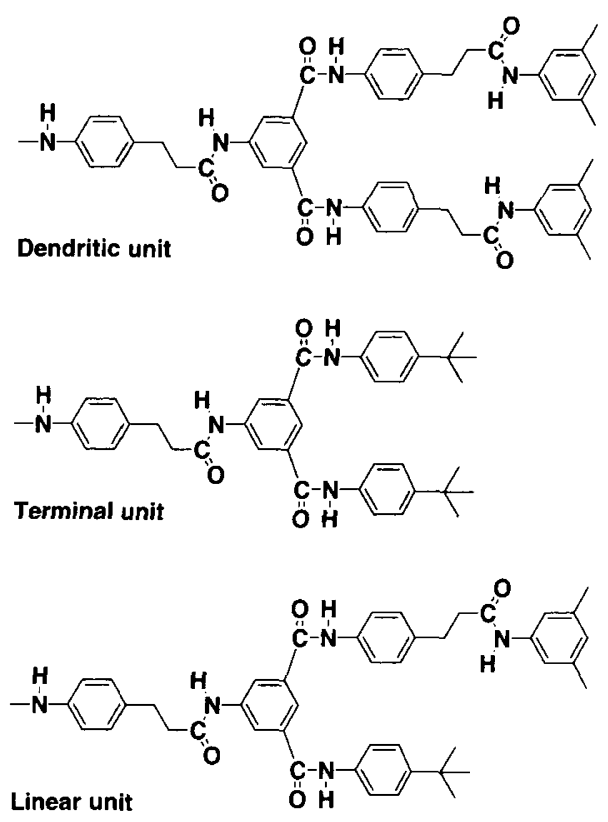

Figure 2. Structure of a repeat unit in dendritic polyamide.

Table I. One-pot synthesis of dendritic polyamides

\begin{tabular}{|c|c|c|c|c|c|}
\hline \multirow{2}{*}{ No. } & \multirow{2}{*}{ Generation } & Yield & $\mathrm{M}^{\mathrm{a}}$ & \multirow{2}{*}{$M_{n}{ }^{\mathrm{b}}$} & \multirow{2}{*}{$M_{w} / M_{n}{ }^{\mathrm{c}}$} \\
\hline & & $\%$ & Calcd. & & \\
\hline $7 a$ & 1st & 91 & 2198 & 2246 & 1.07 \\
\hline $7 \mathrm{~b}$ & 2nd & 94 & 4847 & 5012 & 1.08 \\
\hline $7 \mathrm{c}$ & $3 \mathrm{rd}$ & 98 & 10146 & 10306 & 1.09 \\
\hline $7 d$ & 4 th & 97 & 20742 & 21084 & 1.08 \\
\hline
\end{tabular}
copy. ${ }^{\mathrm{c}}$ Measured by GPC using THF as eluent.

$30 \mathrm{~min}$. Dendritic polyamides $\mathbf{7 a}-\mathbf{7 d}$ were obtained quantitatively and fully characterized by IR and NMR spectroscopy. Molecular weights were close to calculated values and distribution were 1.07-1.09. The 3rd generation dendritic polyamide had high DB of 0.91 . High molecular weight dendritic polymers with narrow molecular weights could be easily synthesized within a few hours by this one-pot synthesis.

Acknowledgment. This study was financially supported by the New Energy and Industrial Technology Development Organization (NEDO) for the project on Technology for Novel High Functional Materials (AIST).

\section{REFERENCES}

1. G. R. Newkome, C. N. Moorefield, and F. Vogtle, "Dendritic Molecules: Concepts, Synthesis and Perspectives," VCH, Weinheim, 1996.

2. a) D. A. Tomalia, A. M. Naylor, and W. A. Goddard, III, Angew. Chem., Int. Ed. Engl., 29, 138 (1990). b) G. R. Newkome, C. N. Moorefield, and G. R. Baker, Aldrichimica Acta, 25, 31 (1992).

3. J. M. J. Fréchet, Science, 263, 1710 (1994).

4. R. Spindler and J. M. J. Fréchet, J. Chem. Soc., Perkin Trans. 1, 913 (1993).

5. K. L. Wooley, C. J. Hawker, and J. M. J. Fréchet, Angew. 


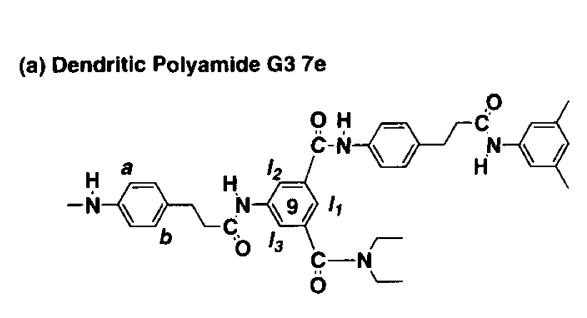

(b) Dendritic model 8a
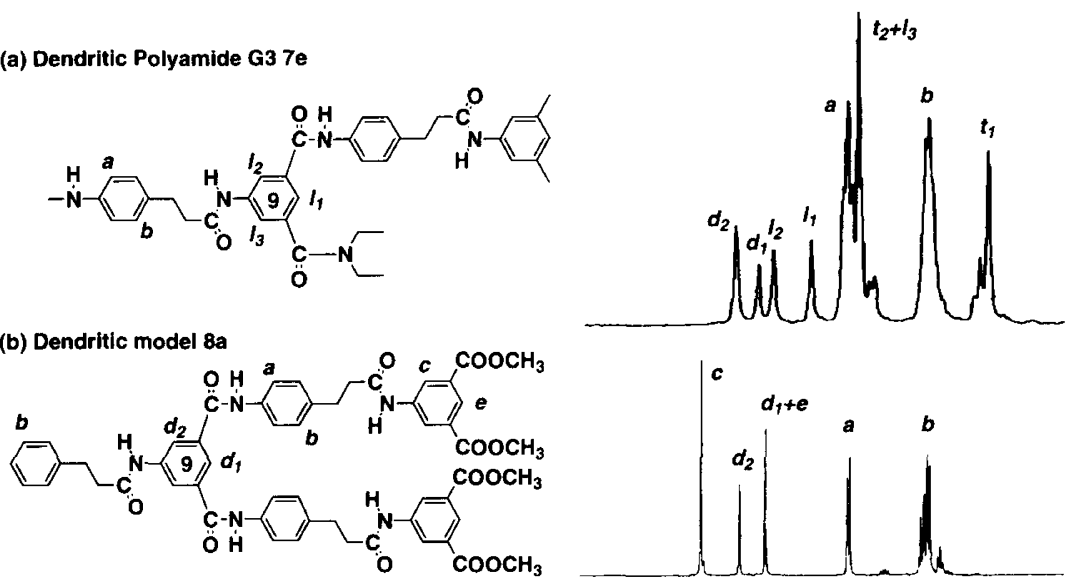

(c) Terminal model $8 \mathrm{~b}$
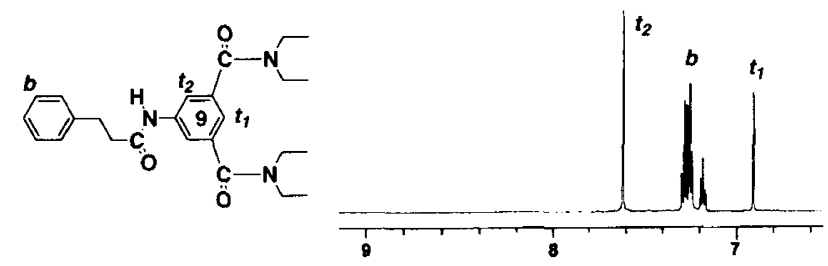

Figure 3. ${ }^{1} \mathrm{H}$ NMR spectra of third generation dendritic polyamide $7 \mathbf{e}(\mathrm{a})$ and model compounds $8 \mathbf{a}$ and $8 \mathbf{b}$ in $\left(\mathrm{CD}_{3}\right)_{2} \mathrm{SO}-d_{6}$.

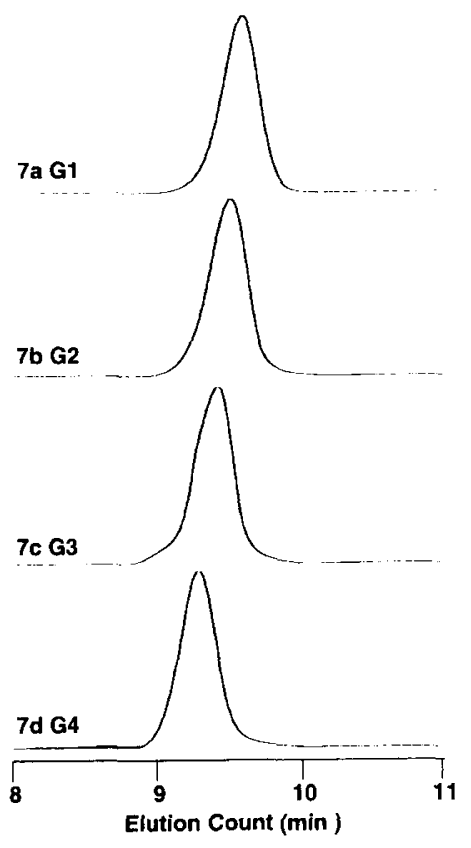

Chem., Int. Ed. Engl., 33, 82 (1994).

6. F. Zeng and S. C. Zimmerman, J. Am. Chem. Soc., 118, 5326 (1996).

7. S. K. Deb, T. M. Maddux, and L. Yu, J. Am. Chem. Soc., 119 9079 (1997).

8. Y. Yamakawa, M. Ueda, R. Nagahata, K. Takeuchi, and M. Asai, J. Chem. Soc., Perkin Trans. 1, 4135 (1998).

9. Y. Yamakawa, M. Ueda, K. Takeuchi, and M. Asai, J. Polym. Sci., Polym. Chem., 37, 3638 (1999).

10. Y. Yamakawa, M. Ueda, K. Takeuchi, and M. Asai, Macromolecules, 32, 8363 (1999).

11. M. Ueda, A. Kameyama, and K. Hashimoto, Macromolecules, 21, 19 (1988)

12. a) D. Hölter, A. Burgath, and H. Frey, Acta Polym., 48, 298 (1997). b) R. Hanselmann, D. Hölter, and H. Frey, Macromolecules, 31, 3790 (1998).

Figure 4. GPC traces of dendritic polyamides. 